\title{
Effects of combined netupitant and palonosetron (NEPA), a cancer supportive care antiemetic, on the ECG of healthy subjects: an ICH E14 thorough QT trial
}

Tulla Spinelli* ${ }^{* *}$ Cecilia Moresino ${ }^{1}$, Sybille Baumann², Wolfgang Timmer ${ }^{2}$ and Armin Schultz ${ }^{2}$

\begin{abstract}
Chemotherapy-induced nausea and vomiting is ranked among the worst side effects of chemotherapy. NEPA is an oral fixed-dose combination antiemetic under development, consisting of netupitant $300 \mathrm{mg}$, a highly selective $\mathrm{NK}_{1}$ receptor antagonist (RA), and palonosetron $0.5 \mathrm{mg}$, a pharmacologically and clinically distinct $5-\mathrm{HT}_{3} \mathrm{RA}$. Although palonosetron is not associated with relevant ECG effects, this study evaluated cardiovascular safety of netupitant in combination with palonosetron, as well as its tolerability.

This randomised, placebo- and positively controlled study in 197 subjects included 4 treatment groups: placebo, $200 \mathrm{mg}$ netupitant $+0.5 \mathrm{mg}$ palonosetron $\left(\mathrm{NEPA}_{200 / 0.5}\right), 600 \mathrm{mg}$ netupitant $+1.5 \mathrm{mg}$ palonosetron $\left(\mathrm{NEPA}_{600 / 1.5}\right.$, a supratherapeutic dose), and $400 \mathrm{mg}$ moxifloxacin. Assessments included a 24-h baseline ECG recording, followed by a single dose of treatment and ECG measurements for 2 days.

Mean placebo-corrected time-averaged changes from baseline were similar in NEPA $200 / 0.5$ and NEPA $\mathrm{N}_{60 / 1.5}$ groups primarily for individually heart rate-corrected QT interval (QTcl: +4.7 and $+3.6 \mathrm{~ms}$, respectively) and for heart rate (HR: $-3.3 \mathrm{bpm}$ and $-3.0 \mathrm{bpm}), \mathrm{PR}$ interval $(-0.4 \mathrm{~ms}$ and $0.2 \mathrm{~ms}$ ), and QRS interval (1 ms and $0.5 \mathrm{~ms})$. The time-matched analysis showed no upper confidence interval $>10 \mathrm{~ms}$, with no suggestion of a QTc effect by pharmacokinetic-pharmacodynamic modeling for parent/metabolites. Moxifloxacin showed the expected placebo-corrected change from baseline ( $+8.4 \mathrm{~ms}$ time average) and the expected profile to establish assay sensitivity. No new morphologic changes of clinical relevance were observed. Treatment-related adverse events were comparable among groups.

This study showed that NEPA treatments produced no significant effects on QTCl, HR, PR interval, QRS interval, and cardiac morphology relative to placebo, even at supratherapeutic doses.
\end{abstract}

Keywords: NEPA; Chemotherapy-induced nausea and vomiting; Netupitant; Palonosetron; QTc; ECG

\section{Background}

Chemotherapy-induced nausea and vomiting (CINV) is a common and distressing consequence of cytotoxic chemotherapy. Acute CINV is described as CINV occurring in the first 24 hours after administration of chemotherapy, whereas delayed CINV begins 25 hours or more after chemotherapy initiation, and can last up to several days after chemotherapy is completed

\footnotetext{
* Correspondence: tulla.spinelli@helsinn.com

${ }^{1}$ Helsinn Healthcare SA, Via Pian Scairolo 9, 6912 Lugano/Pazzallo,

Switzerland

Full list of author information is available at the end of the article
}

(Bloechl-Daum et al. 2006; Hesketh et al. 2003). CINV impacts patients' quality of life and is a major reason for noncompletion or delay of the chemotherapy programme (Bloechl-Daum et al. 2006; Aapro et al. 2012; Cohen et al. 2007).

There are 2 major pathways known to be involved in CINV. The neurotransmitter serotonin (5-hydroxytryptamine or $5-\mathrm{HT}$ ) has been shown to be an important mediator of the acute phase, while the role of substance $\mathrm{P}$ is mainly related to the delayed phase of CINV (Hesketh et al. 2003; Rojas and Slusher 2012; Feyer and Jordan 2011; Rubenstein et al. 2006). Preclinical studies demonstrated 
that cisplatin causes increased levels in the peripheral circulation of both serotonin and substance P. The $5-\mathrm{HT}_{3}$ receptor antagonists (RAs) are thought to inhibit the serotonin emetic pathway peripherally, while the neurokinin $1\left(\mathrm{NK}_{1}\right)$ RAs are thought to act on the substance $\mathrm{P}$-mediated signaling at the level of the central nervous system (Hesketh et al. 2003; Rojas and Slusher 2012; Feyer and Jordan 2011; Rubenstein et al. 2006).

International antiemetic guidelines recommend administering a $5-\mathrm{HT}_{3} \mathrm{RA}$ with an $\mathrm{NK}_{1} \mathrm{RA}$ and a corticosteroid as part of the antiemetic regimen to prevent nausea and vomiting in patients who are at high risk to develop it (Basch et al. 2011; Gralla et al. 2013; Roila et al. 2010; National Comprehensive Cancer Network 2013). Nevertheless, CINV is still underestimated, particularly in the delayed phase and with regard to nausea (Bloechl-Daum et al. 2006; Cohen et al. 2007; Salsman et al. 2012; Roscoe et al. 2004). This represents an area of need that should be addressed by new and safe antiemetics.

NEPA is a new antiemetic under development that targets a dual antiemetic pathway with a single oral fixeddose combination of netupitant $300 \mathrm{mg}$ and palonosetron $0.5 \mathrm{mg}$ to be administered prior to emetogenic chemotherapy. The phase II and III pivotal clinical studies demonstrating both the safety and high efficacy of this convenient single-day antiemetic have recently been published (Hesketh et al. 2014; Aapro et al. 2014; Gralla et al. 2014). Netupitant (2-(3,5-Bis-trifluoromethyl-phenyl)-Nmethyl-N-[6-(4-methyl-piperazin-1-yl)-4-o-tolyl-pyridine3-yl]-isobutyramide) is a new and selective $\mathrm{NK}_{1} \mathrm{RA}$ showing a high receptor occupancy level at time to maximum plasma concentration ( $t_{\max }$; more than $90 \%$ ) and a long-lasting (up to 96 hours postdose) blockade of $\mathrm{NK}_{1}$ receptors in the human brain (Spinelli et al. 2014). Chronic administration of different daily doses of netupitant (50 mg, $100 \mathrm{mg}$, and $200 \mathrm{mg}$ ) for 8 weeks raised no safety issues in patients with an overactive bladder (Haab et al. 2014). Palonosetron ((3aS)-2-[(S)-1Azabicyclo[2.2.2] oct-3-yl]-2,3,3a,4,5,6-hexahydro-1-oxo-1H benz[de]isoquinoline hydrochloride) is a $5-\mathrm{HT}_{3} \mathrm{RA}$ with a longer half-life and higher binding affinity that differs from traditional setrons both from a pharmacologic and clinical point of view (Reddy et al. 2006). In vitro and in vivo studies demonstrated that palonosetron uniquely: 1) exhibits allosteric binding to the $5-\mathrm{HT}_{3}$ receptor, with positive cooperativity and persistent inhibition of receptor function; 2) triggers $5-\mathrm{HT}_{3}$ receptor internalisation; and 3) inhibits substance Pmediated response through inhibition of the $5-\mathrm{HT}_{3}$ and $\mathrm{NK}_{1}$ receptor cross-talk (Rojas and Slusher 2012). Several studies have shown that palonosetron, as a single agent or in combination with a corticosteroid, has a high tolerability profile and achieves superior efficacy in preventing CINV compared with the other $5-\mathrm{HT}_{3} \mathrm{RAs}$
(Aapro et al. 2006; Eisenberg et al. 2003; Gralla et al. 2003; Saito et al. 2009).

Preclinical data demonstrated that NEPA synergistically enhanced inhibition of the substance $\mathrm{P}$ response compared to either palonosetron or netupitant alone (Stathis et al. 2012). These data suggest that the NEPA combination represents an effective and convenient approach to prevent acute and delayed CINV with a single oral dose.

Cardiovascular disease represents one of the most common comorbidities in the growing population of cancer patients aged more than 65 years (Aapro et al. 2005). Cardiopathy can be preexisting or a consequence of the malignancy, and ECG changes can be an adverse event (AE) resulting from chemotherapy treatment. Several antineoplastic agents (especially anthracyclines) and some platinum compounds are associated with ECG alterations, including prolongation of the QT interval, development of ventricular late potentials, and various arrhythmias. It has been shown that the interaction of anthracyclines with the monoclonal antibody trastuzumab, which is quite common in breast cancer patients, can potentiate cardiotoxic effects (Bagnes et al. 2010). Cyclophosphamide treatment has been associated with $7 \%$ to $28 \%$ incidence of heart failure, while cisplatin has been associated with $8.5 \%$ of venous thromboembolism incidence (Vo and Nelson 2012). The use of 5-fluorouracil has been reported to be associated with ECG changes (eg, ST segment deviation and corrected QT interval [QTc] prolongation in nearly $68 \%$ of patients) and cardiotoxicity (eg, angina, supraventricular tachycardia, and myocardial infarction with an incidence of 1\%-18\%) (Sorrentino et al. 2012). Cardiotoxicity has also been reported after administration of taxanes (eg, brady- and tachyarrhythmia and other cardiac disturbances) (Bagnes et al. 2010; Yeh and Bickford 2009). The incidence of bradycardia associated with paclitaxel treatment ranges from $<0.1 \%$ to $31 \%$ and the incidence of heart failure associated with docetaxel treatment ranges from $<2.3 \%$ to $8 \%$ (Yeh and Bickford $2009)$. Both paclitaxel ( $<1 \%-5 \%$ incidence) and docetaxel (1.7\% incidence) have been associated with myocardial ischaemia (Yeh and Bickford 2009).

Not only chemotherapeutic agents, but also newer targeted agents have been shown to lead to cardiotoxicity (Bagnes et al. 2010; Hedhli and Russell 2011). Multikinase-targeted drugs (eg, sorafenib, sunitinib, imatinib, and dasatinib) are associated with various cardiac effects, such as hypertension, congestive heart failure, and QTc prolongation (Bagnes et al. 2010; Hedhli and Russell 2011). The use of histone deacetylase inhibitors has also been associated with QTc prolongation (Bagnes et al. 2010; Hedhli and Russell 2011). Administration of anti-vascular endothelial growth factor agents (eg, bevacizumab and aflibercept) can lead to hypertension, arrhythmia, and thromboembolic effects, such as 
myocardial infarction (Bagnes et al. 2010; Hedhli and Russell 2011).

The current double-blind, randomised, parallel-group study evaluated whether the combined administration of different doses of netupitant + palonosetron prolongs the individually heart rate-corrected QT interval (QTcI) more than placebo. Safety and tolerability of the combination therapy, as well as pharmacokinetic (PK) data, were evaluated.

\section{Methods}

\section{Study design and treatment}

This was a phase I, randomised, double-blind (except for the use of moxifloxacin), double-dummy, parallelgroup, placebo- and open-label positively controlled study (EudraCT: 2007-004365-17). The study was approved by appropriate ethics committees and was conducted in accordance with the Declaration of Helsinki, the German Drug Law, and the German Good Clinical Practice decree. All subjects gave written informed consent to participate in the trial. The primary objective of this study was to assess whether the combined administration of different doses of netupitant + palonosetron prolongs QTcI more than placebo. Secondary objectives were to evaluate the safety and tolerability of NEPA combinations and assess the PK of netupitant, palonosetron, and their metabolites.

The trial design followed the provisions of ICH Guideline E14 for a "thorough QT/QTc study" (US Department of Health and Human Services 2005). The study consisted of an ambulant screening phase (days -21 to -3 ), a pre-check period (day -2 and -1 ), a treatment period (days 1-3), and an ambulant final check 14 to 21 days after discharge from the study center on day 3 . Subjects were hospitalised from the evening of day -2 until day 3 . Subjects were randomly assigned to one of the following single-dose treatment groups: placebo, $200 \mathrm{mg}$ netupitant $+0.50 \mathrm{mg}$ palonosetron $\left(\mathrm{NEPA}_{200 / 0.5}\right), 600 \mathrm{mg}$ netupitant $+1.50 \mathrm{mg}$ palonosetron $\left(\mathrm{NEPA}_{600 / 1.5}\right)$, and $400 \mathrm{mg}$ moxifloxacin (Avelox ${ }^{\oplus}$, Bayer Healthcare; positive control). A 24-hour baseline ECG was followed by a single dose of treatment on day 1 , after which subjects had ECG and PK measurements up to 48 hours postdose.

\section{Subjects}

Two hundred healthy subjects (at least 92 of each gender) aged 18 to 45 years were included if they had a body mass index of 19 to $<29 \mathrm{~kg} / \mathrm{m}^{2}$, were nonsmokers (or refrained from smoking or taking other nicotine-containing products for 3 months prior to dosing), and had normal blood pressure $(55-89 / 95-149 \mathrm{mmHg})$ and pulse rate $(45-95$ beats/minute). Subjects with any of the following were excluded: current use of oral contraceptives or hormones within 3 months prior to dosing; pregnant or breastfeeding; use of prescribed or over-the-counter medication within 14 days of dosing; any active physical disease (acute or chronic); gastrointestinal complaints within 7 days of dosing; febrile or infectious illness within 7 days of dosing; any cardiovascular condition; any abnormal ECG interval or changes in ECG that might interfere with measurement of QT interval; relevant drug hypersensitivity (specifically against moxifloxacin); known contraindication to $\mathrm{NK}_{1}$ RAs, 5- $\mathrm{HT}_{3} \mathrm{RAs}$, or fluoroquinolones; positive test for hepatitis $B$ virus, hemoglobin $C$, or human immunodeficiency virus; or any other reason deemed unsuitable in the opinion of the investigator.

\section{Pharmacodynamics}

ECGs were obtained using a continuous 12-lead digital Holter recorder (Mortara H-12; Milwaukee, WI) on day -1 (baseline) and on days 1 and 2. ECGs to be used in the analysis were selected at the following predetermined time points: day -1 at $-23,-22,-20,-19,-18,-17,-16,-14$, $-12,-10,-8,-6$, and -0.5 hours; days 1 and 2 at $1,2,4,5$, $6,7,8,10,12,14,16,18,23.5,30,36,42$, and 47.5 hours. Four ECGs were obtained at each time point. Three kinds of QTc were calculated. The primary ECG endpoint was QTcI, calculated as QTcI $=\mathrm{QT} /(\mathrm{RR})^{\text {slope }}$, where the slope was determined for each subject by linear regression analysis on the baseline ECGs. Secondary ECG variables included frequency correction performed using the Fridericia formula (QTcF) and frequency correction performed using Bazett formula (QTcB). Additionally, the following parameters were evaluated: uncorrected QT interval, heart rate (HR), PR interval, QRS interval, and change in ECG morphologic patterns.

\section{Pharmacokinetics}

The area under the plasma concentration-time curve data from administration until the last sampling point $\left(\mathrm{AUC}_{0-\mathrm{t}}\right)$, maximum plasma concentration $\left(\mathrm{C}_{\max }\right)$, and $t_{\max }$ were determined for netupitant (and its metabolites M1, M2, and M3) and palonosetron (and its metabolites M4 and M9), if data permitted. $\mathrm{AUC}_{0-\mathrm{t}}$ was calculated by the linear trapezoidal formula, $\mathrm{C}_{\max }$ was defined as the highest observed plasma concentration of the measured concentration-time profile, and $t_{\max }$ was set as the time after administration at which $\mathrm{C}_{\max }$ occurred.

A simultaneous, validated, internally standardised liquid chromatography-tandem mass spectrometry (LC-MS/MS) method with electrospray ionisation in the positive mode was used for the analysis of netupitant and its metabolites M1, M2, and M3 and palonosetron and its metabolites M4 and M9. The analytics methods used for determination of netupitant and palonosetron and their metabolites are validated and approved by the US Food and Drug Administration and European Medicines Agency guidelines and were performed accordingly. 


\section{Safety and tolerability parameters}

Safety and tolerability parameters included physical examination, vital signs, body temperature, body weight, ECG recording, and laboratory examinations (clinical chemistry, haematology, urinalysis, serology, drug screen and alcohol breath test, and pregnancy test). AEs were ascertained and rated by the investigators. Overall tolerability was assessed by the investigator at the end of the study.

\section{Statistics methods}

Biometric and PK evaluation were carried out using SAS $^{\circ}$ (Version 9.1). Descriptive statistics were used to summarise demographic data and ECG variables at each time point. For the QTc analysis, 2-sided 90\% confidence intervals (CIs) based on the intersection-union test were calculated for each matched time (time-matched analysis). If the upper limit of the 2-sided $90 \%$ CI for the study treatment versus placebo did not exceed 10 milliseconds (ms) at any time point, it was concluded that this dose did not prolong the QTc interval to a clinically significant degree. To establish assay sensitivity, at least 1 time point with a mean difference of moxifloxacin and placebo $>5 \mathrm{~ms}$ had to be observed.

In addition to the time-matched analysis, the timeaveraged analysis was calculated. For each subject and for the ECG parameters QTc (I, B, F), HR, PR, QRS, and QT, the mean of all baseline ECGs was calculated as the time-averaged baseline value, and the mean of all postdose ECGs was calculated as the time-averaged postdose value. The time-averaged change from baseline was calculated from both values. The placebo-corrected time-averaged change from baseline was calculated by subtracting the mean placebo baseline-corrected values from the mean time-averaged change from baseline of the other treatment groups.

The PK/pharmacodynamics (PD) analysis explored the relationship between the placebo-adjusted QTcI change from baseline and plasma concentrations of netupitant and palonosetron. A linear mixed-effects modeling approach was adopted in which this PK/PD relationship was a fixed effect with subject included as a random effect $(\Delta \Delta \mathrm{QTCI}=\alpha+\beta *$ [plasma concentration $]+\gamma *$ [subject effect]). This model was used to estimate the population slope and the standard error (SE) of the slope. A linear relationship was declared if the $\mathrm{p}$-value of the slope was $<0.05$. The mean maximum effect $\left(C_{\max } * \beta\right)$ and the upper 1-sided 95\% CI $\left(C_{\max } * \beta+[1.65 * \operatorname{SE} \beta *\right.$ $\left.\mathrm{C}_{\text {max }}\right]$ ) were calculated.

A sample size of 50 subjects per group was expected to provide at least $80 \%$ power to show for the comparison of netupitant/palonosetron to placebo that the upper limit of the $90 \%$ CI falls below $10 \mathrm{~ms}$. The sample size was calculated based on an assumed standard deviation of $11 \mathrm{~ms}$. The true difference between time-matched changes from baseline QTcI of netupitant/palonosetron and placebo groups was selected as $3 \mathrm{~ms}$.

\section{Results}

\section{Disposition and baseline characteristics}

Two hundred subjects (106 males and 94 females) were enrolled in the study. Five women withdrew consent and discontinued the study. Three of them withdrew their consent before treatment administration and were therefore not included in any analysis. One subject in the $\mathrm{NEPA}_{200}$ / 0.5 group did not show netupitant plasma levels and was therefore excluded from the PD analyses. One hundred ninety-five subjects completed the study. The baseline characteristics of the study population were comparable between treatment groups and are shown in Table 1.

\section{Pharmacodynamics}

One hundred ninety-six subjects were included in the PD analyses. Because heart rate inversely affects QT duration, the assessment of cardiac repolarisation was based on QTcI. The QTcI mean time-averaged placebocorrected change from baseline for $\mathrm{NEPA}_{200 / 0.5}$ and $\mathrm{NEPA}_{600 / 1.5}$ was +4.7 and $+3.6 \mathrm{~ms}$, respectively (Table 2). For QTcB, values were -0.9 and $-0.5 \mathrm{~ms}$ for $\mathrm{NEPA}_{200 / 0.5}$ and $\mathrm{NEPA}_{600 / 1.5}$ groups, respectively. For the time-averaged analysis, the mean placebo-corrected change from baseline for heart rate was similar for the $\mathrm{NEPA}_{200 / 0.5}$ and $\mathrm{NEPA}_{600 / 1.5}$ groups $(-3.3$ and $-3.0 \mathrm{bpm}$, respectively; Table 2). Mean placebo-corrected change from baseline for PR and QRS durations was similar for the $\mathrm{NEPA}_{200 / 0.5}$ (PR: $-0.4 \mathrm{~ms}$; QRS: $1.0 \mathrm{~ms}$ ) and $\mathrm{NEPA}_{600 / 1.5}$ (PR: $0.2 \mathrm{~ms}$; QRS: $0.5 \mathrm{~ms}$ ) groups, and was not considered clinically relevant (Table 2).

These data showed no signs for an effect of different doses of netupitant + palonosetron on QTc (Table 2). In the moxifloxacin-treated group, the placebo-corrected mean change from baseline for QTcI and QTcB values was +8.4 and $+8.5 \mathrm{~ms}$, respectively (expected $5-10 \mathrm{~ms}$ ), indicating assay sensitivity was reached (Table 2). In the placebo group the QTcI and QTcB mean changes from baseline were -2.1 and $-3.0 \mathrm{~ms}$, respectively, showing that background QTc was controlled (Table 2).

A time-matched analysis was conducted as recommended by ICH E14 with placebo- and baseline-corrected QTcI data for NEPA and moxifloxacin dose groups. The analysis for QTcI revealed that the moxifloxacin group met the assay sensitivity criteria with 12 time points above a mean of $5 \mathrm{~ms}$ (Table 3, Figure 1a). Results showed that the NEPA groups did not exceed the upper CI of $10 \mathrm{~ms}$ at any of the time points (Table 3, Figure 1a). Therefore, the combination of different doses of netupitant and palonosetron did not prolong the QTc interval to a clinically significant degree. 
Table 1 Baseline characteristics

\begin{tabular}{|c|c|c|c|c|}
\hline & Placebo $(\mathrm{N}=50)$ & $\mathrm{NEPA}_{200 / 0.5}(\mathrm{~N}=49)$ & $\mathrm{NEPA}_{600 / 1.5}(\mathrm{~N}=49)$ & Moxifloxacin $(\mathrm{N}=49)$ \\
\hline \multicolumn{5}{|l|}{ Age, years } \\
\hline Mean (SD) & $34.7(7.12)$ & $33.6(6.86)$ & $32.8(8.36)$ & 34.7 (7.98) \\
\hline Min-max & $19-45$ & $21-44$ & $19-45$ & $19-45$ \\
\hline \multicolumn{5}{|l|}{ Gender, n (\%) } \\
\hline Male & $26(52)$ & $27(55)$ & $27(55)$ & $26(53)$ \\
\hline Female & $24(48)$ & $22(45)$ & $22(45)$ & $23(47)$ \\
\hline \multicolumn{5}{|l|}{$\mathrm{BMI}, \mathrm{kg} / \mathrm{m}^{2}$} \\
\hline Mean (SD) & $24.45(2.486)$ & $24.27(2.608)$ & $24.51(2.516)$ & $24.89(2.674)$ \\
\hline Min-max & $19.0-28.9$ & $19.2-28.5$ & $19.4-28.9$ & $19.4-29.0$ \\
\hline
\end{tabular}

BMI, body mass index; SD, standard deviation.

$\mathrm{NEPA}_{200 / 0.5}: 200 \mathrm{mg}$ netupitant $(50 \mathrm{mg}+150 \mathrm{mg})+0.50 \mathrm{mg}$ palonosetron $(1 \times 0.50 \mathrm{mg})$.

NEPA $_{600 / 1.5}: 600 \mathrm{mg}$ netupitant $(4 \times 150 \mathrm{mg})+1.50 \mathrm{mg}$ palonosetron $(3 \times 0.50 \mathrm{mg})$.

Percentages are based on $\mathrm{N}$.

No significant gender effect was observed. Morphologic changes were not considered clinically significant in any dose group and there were no imbalances in the $\mathrm{NEPA}_{200 / 0.5}$ and $\mathrm{NEPA}_{600 / 1.5}$ groups.

\section{Pharmacokinetics}

PK parameters were assessed for netupitant and its metabolites M1, M2, and M3 and palonosetron and its metabolites M9 and M4.

A dose-proportional increase of the geometric mean $\mathrm{AUC}_{0-\mathrm{t}}$ was observed for netupitant $(4079 \mathrm{~h} * \mu \mathrm{g} / \mathrm{L}$ at $200 \mathrm{mg}$ to $12213 \mathrm{~h} * \mu \mathrm{g} / \mathrm{L}$ at $600 \mathrm{mg}$ ) and palonosetron $(22641 \mathrm{~h} * \mathrm{ng} / \mathrm{L}$ at $0.5 \mathrm{mg}$ to $67918 \mathrm{~h} * \mathrm{ng} / \mathrm{L}$ at $1.5 \mathrm{mg})$. Similarly, $\mathrm{C}_{\max }$ increased with dose for both netupitant $(219 \mu \mathrm{g} / \mathrm{L}$ to $648 \mu \mathrm{g} / \mathrm{L})$ and palonosetron $(822 \mathrm{ng} / \mathrm{L}$ to 2588 ng/L; Table 4). The intersubject PK variability was higher for netupitant than for palonosetron. The intersubject variability of netupitant for $\mathrm{AUC}_{0-\mathrm{t}}$ and $\mathrm{C}_{\max }$ was $42 \%$ and $48 \%$ at $200 \mathrm{mg}$, and $47 \%$ and $56 \%$ at $600 \mathrm{mg}$. For palonosetron, the intersubject variability for AUC $_{0-\mathrm{t}}$ and $\mathrm{C}_{\max }$ varied from $20 \%$ to $29 \%$. The pharmacokinetics of netupitant and palonosetron, including their metabolites, confirm that the ECG time points were adequately chosen, since the $C_{\max }$ of all analytes lie within the ECG measurement time points.

\section{Pharmacodynamics/pharmacokinetics relationship}

The relationship between placebo- and baseline-corrected QTcI duration and plasma concentration from paired samples taken in both dose groups for netupitant (Figure 1b) and palonosetron (Figure 1c) was evaluated. There were no indications that exposure to netupitant or palonosetron (parent or M1, M2, or M3 metabolites for netupitant; M9 or M4 metabolite for palonosetron) induced changes in

Table 2 Time-averaged analysis: mean changes from baseline

\begin{tabular}{|c|c|c|c|c|c|c|c|c|}
\hline \multirow[b]{2}{*}{ Endpoint } & \multirow[b]{2}{*}{ Parameter } & \multirow{2}{*}{$\begin{array}{c}\text { Placebo }(\mathrm{N}=50) \\
\text { Change } \\
\text { from } \\
\text { baseline }\end{array}$} & \multicolumn{2}{|c|}{$\mathrm{NEPA}_{200 / 0.5}(\mathrm{~N}=48)$} & \multicolumn{2}{|c|}{$\mathrm{NEPA}_{600 / 1.5}(\mathrm{~N}=49)$} & \multicolumn{2}{|c|}{ Moxifloxacin $(\mathrm{N}=49)$} \\
\hline & & & $\begin{array}{l}\text { Change } \\
\text { from } \\
\text { baseline }\end{array}$ & $\begin{array}{c}\text { Placebo-corrected } \\
\text { change from } \\
\text { baseline }\end{array}$ & $\begin{array}{l}\text { Change } \\
\text { from } \\
\text { baseline }\end{array}$ & $\begin{array}{c}\text { Placebo-corrected } \\
\text { change from } \\
\text { baseline }\end{array}$ & $\begin{array}{l}\text { Change } \\
\text { from } \\
\text { baseline }\end{array}$ & $\begin{array}{c}\text { Placebo-corrected } \\
\text { change from } \\
\text { baseline }\end{array}$ \\
\hline \multirow[t]{2}{*}{ Primary } & QTcl, ms & -2.1 & 2.6 & 4.7 & 1.5 & 3.6 & 6.3 & 8.4 \\
\hline & (Min;max) & $(-8.3 ; 4.8)$ & $(-5.8 ; 30.6)$ & & $(-7.3 ; 14.3)$ & & $(-2.6 ; 15.3)$ & \\
\hline \multirow[t]{6}{*}{ Secondary } & $\mathrm{HR}$, bpm & -0.7 & -4.0 & -3.3 & -3.7 & -3.0 & -0.4 & 0.3 \\
\hline & $\mathrm{PR}, \mathrm{ms}$ & 1.1 & 0.7 & -0.4 & 1.3 & 0.2 & -0.2 & -1.3 \\
\hline & QRS, ms & -0.3 & 0.7 & 1.0 & 0.2 & 0.5 & 0.0 & 0.3 \\
\hline & $\mathrm{QT}, \mathrm{ms}$ & -0.4 & 9.3 & 9.7 & 8.6 & 9.0 & 6.9 & 7.3 \\
\hline & QTcF, ms & -2.1 & 0.5 & 2.6 & 0.5 & 2.6 & 6.0 & 8.1 \\
\hline & $\mathrm{QTCB}, \mathrm{ms}$ & -3.0 & -3.9 & -0.9 & -3.5 & -0.5 & 5.5 & 8.5 \\
\hline
\end{tabular}

bpm, beats per minute; min, minimum; max, maximum; HR, heart rate; ms, milliseconds; QTcB, Bazett correction; QTcF, Fridericia correction; QTcl, individually heart rate-corrected QT interval.

$\mathrm{NEPA}_{200 / 0.5}: 200 \mathrm{mg}$ netupitant $(50 \mathrm{mg}+150 \mathrm{mg})+0.50 \mathrm{mg}$ palonosetron $(1 \times 0.50 \mathrm{mg})$.

NEPA $600 / 1.5: 600 \mathrm{mg}$ netupitant $(4 \times 150 \mathrm{mg})+1.50 \mathrm{mg}$ palonosetron $(3 \times 0.50 \mathrm{mg})$. 
Table 3 Time-matched analysis: placebo and baseline corrected QTcl data for NEPA and moxifloxacin dose groups

\begin{tabular}{|c|c|c|c|c|c|c|}
\hline \multirow[t]{2}{*}{ Time, $\mathrm{h}$} & \multicolumn{2}{|c|}{$\mathrm{NEPA}_{200 / 0.5}$} & \multicolumn{2}{|c|}{$\mathrm{NEPA}_{600 / 1.5}$} & \multicolumn{2}{|c|}{ Moxifloxacin } \\
\hline & Estimate $^{1}$ & Upper bound $^{2}$ & Estimate $^{1}$ & Upper bound ${ }^{2}$ & Estimate $^{1}$ & Upper bound $^{2}$ \\
\hline 1 & 3.2 & 5.2 & 3.5 & 5.3 & 12.2 & 15.1 \\
\hline 2 & 3.8 & 5.9 & 1.0 & 2.8 & 12.7 & 15.6 \\
\hline 4 & 5.5 & 7.6 & 1.7 & 3.5 & 13.7 & 16.6 \\
\hline 5 & 4.8 & 6.9 & 2.5 & 4.3 & 12.2 & 15.1 \\
\hline 6 & 3.5 & 5.6 & 4.3 & 6.1 & 9.7 & 12.6 \\
\hline 7 & 4.5 & 6.5 & 4.1 & 5.9 & 10.5 & 13.4 \\
\hline 8 & 5.3 & 7.4 & 4.3 & 6.1 & 9.6 & 12.6 \\
\hline 10 & 6.1 & 8.1 & 5.2 & 7.0 & 10.8 & 13.7 \\
\hline 12 & 5.7 & 7.8 & 3.6 & 5.4 & 9.2 & 12.1 \\
\hline 14 & 6.7 & 8.7 & 4.9 & 6.7 & 7.5 & 10.4 \\
\hline 16 & 5.5 & 7.6 & 7.0 & 8.8 & 8.0 & 10.9 \\
\hline 18 & 6.0 & 8.1 & 5.3 & 7.1 & 7.1 & 10.0 \\
\hline 23.5 & 1.7 & 3.7 & 3.3 & 5.1 & 4.7 & 7.6 \\
\hline 30 & 4.9 & 7.0 & 4.4 & 6.2 & 5.2 & 8.1 \\
\hline 36 & 3.9 & 6.0 & 3.2 & 5.0 & 3.8 & 6.7 \\
\hline 42 & 4.3 & 6.4 & 0.8 & 2.6 & 3.0 & 5.9 \\
\hline 47.5 & 1.8 & 3.8 & 0.6 & 2.4 & 2.3 & 5.3 \\
\hline Time average & 4.6 & 5.7 & 3.4 & 4.5 & 8.4 & 9.5 \\
\hline
\end{tabular}

ANOVA, analysis of variance; QTCl, individually heart rate-corrected QT interval.

NEPA $_{200 / 0.5}: 200 \mathrm{mg}$ netupitant $(50 \mathrm{mg}+150 \mathrm{mg})+0.50 \mathrm{mg}$ palonosetron $(1 \times 0.50 \mathrm{mg})$.

$\mathrm{NEPA}_{600 / 1.5}: 600 \mathrm{mg}$ netupitant $(4 \times 150 \mathrm{mg})+1.50 \mathrm{mg}$ palonosetron $(3 \times 0.50 \mathrm{mg})$.

${ }^{1}$ Mixed-model ANOVA is fit for placebo-corrected change from baseline and includes terms for treatment, gender, time, and a time-by-treatment interaction.

${ }^{2}$ Upper bound, upper 1-sided 95\% ANOVA model-based confidence limit.

QTc parameters. All estimated slopes were close to 0 and no upper CI approached $10 \mathrm{~ms}$.

\section{Safety and tolerability}

During the study, a total of 60 AEs were reported by 49 subjects. AEs were reported for $12(24.0 \%)$ subjects in the placebo, $10(20.4 \%)$ in the $\mathrm{NEPA}_{200 / 0.5}, 17(34.7 \%)$ in the $\mathrm{NEPA}_{600 / 1.5}$, and $10(20.4 \%)$ in the moxifloxacin groups. Possibly or probably treatment-related AEs (TRAEs) were reported for $9(18.0 \%)$ placebo subjects and $8(16.3 \%)$, $10(20.4 \%)$, and $8(16.3 \%)$ subjects in the $\mathrm{NEPA}_{200 / 0.5}$, $\mathrm{NEPA}_{600 / 1.5}$, and moxifloxacin groups, respectively (Table 5). The incidence of TRAEs in the $\mathrm{NEPA}_{200 / 0.5}$ group was comparable to that of the placebo and moxifloxacin groups, although the frequency of TRAEs was slightly higher with $\mathrm{NEPA}_{600 / 1.5}$. With $\mathrm{NEPA}_{200 / 0.5}$ treatment, most commonly reported TRAEs were constipation ( 3 subjects), followed by upper abdominal pain ( 2 subjects), and headache (2 subjects). In the $\mathrm{NEPA}_{600 / 1.5}$ group, headache (5 subjects) was most commonly reported, followed by constipation ( 2 subjects). Subjects treated with moxifloxacin reported mainly dizziness (3 subjects) and headache ( 2 subjects).

No deaths occurred during the study. One subject had a serious AE (injury) caused by a staircase accident and recovered by the end of the study. The investigator assessed the event as unlikely related to study drug. No clinically significant laboratory changes were observed and there were no AEs associated with laboratory changes. No abnormalities were detected in vital signs or ECG. The overall tolerability was assessed as good in 193 subjects and as satisfactory in 4 subjects.

\section{Discussion}

NEPA is an oral fixed-dose combination of netupitant $300 \mathrm{mg}$ and palonosetron $0.5 \mathrm{mg}$ targeting dual antiemetic pathways mediated by serotonin and substance $\mathrm{P}$ with a single administration on the day of chemotherapy. Since the incidence of cancer patients with cardiovascular-related diseases is growing, especially in the elderly population, the cardiac safety profile of drugs used for supportive care should be investigated.

As recommended by international antiemetic guidelines, especially in patients undergoing highly emetogenic chemotherapy, an $\mathrm{NK}_{1} \mathrm{RA}$, a $5-\mathrm{HT}_{3} \mathrm{RA}$, and a corticosteroid are commonly coadministered to prevent CINV (Basch et al. 2011; Gralla et al. 2013; Roila et al. 2010; National Comprehensive Cancer Network 2013). Aprepitant and its prodrug fosaprepitant are the only $\mathrm{NK}_{1} \mathrm{RAs}$ currently available and used in clinical practice. A recent 


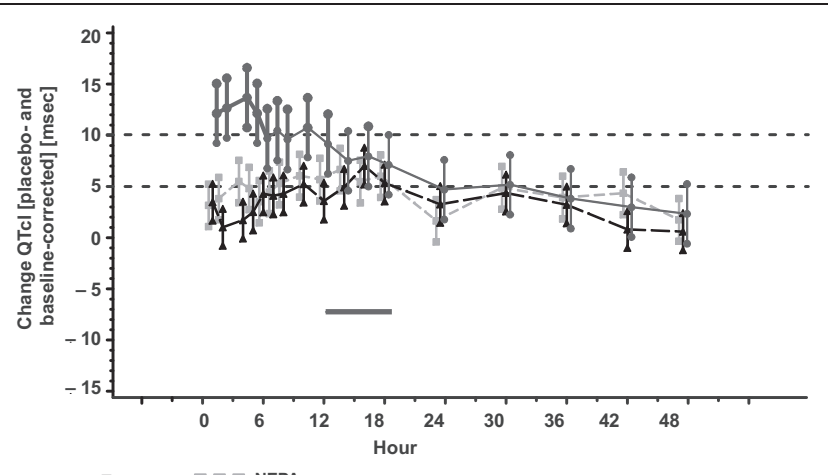

Treatment NEPA $_{2000.5}$

Moxifloxacin $400 \mathrm{mg}$

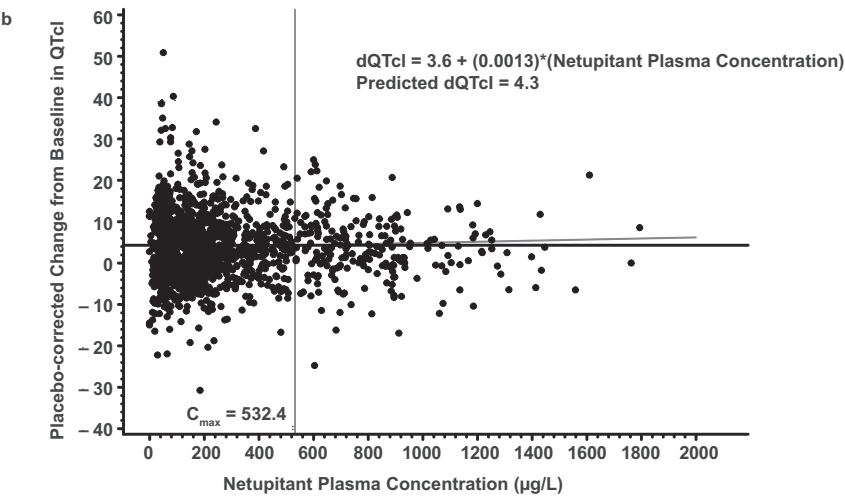

Estimate of the slope of the relationship between plasma concentration of netupitant and the predicted QTc change at $\mathrm{C}_{\text {max }}$

\begin{tabular}{|c|c|c|c|c|c|c|}
\hline $\begin{array}{c}\text { QT } \\
\text { Parameter }\end{array}$ & $\begin{array}{c}\text { Slope of } \\
\text { Plasma } \\
\text { Concentration }\end{array}$ & $\begin{array}{c}\text { Standard } \\
\text { Error } \\
\text { Plasma } \\
\text { Concentration }\end{array}$ & $\mathrm{p}$-value & $\begin{array}{c}\text { Predicted } \\
\text { QTc } \\
\text { at Average } \\
C_{\max } \\
532 \mu \mathrm{g} / \mathrm{L}\end{array}$ & $\begin{array}{c}\text { One-sided } \\
\text { Upper } 95 \% \\
\text { Confidence } \\
\text { Bound of } \\
\text { Predicted QTc }\end{array}$ & $\begin{array}{c}\text { Overall } \\
\text { Model } \\
\text { Fit }\end{array}$ \\
\hline QTcl & 0.0013 & 0.0009 & 0.1267 & 4.3405 & 5.1975 & $<.0001$ \\
\hline
\end{tabular}

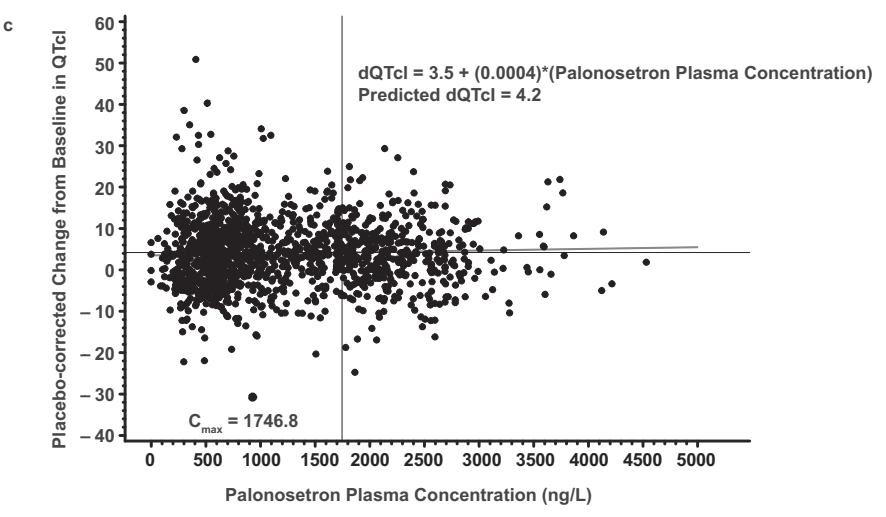

Estimate of the slope of the relationship between plasma concentration of palonosetron and the predicted QTc change at $\mathrm{C}_{\max }$

\begin{tabular}{ccccccc}
\hline $\begin{array}{c}\text { QT } \\
\text { Parameter }\end{array}$ & $\begin{array}{c}\text { Slope of } \\
\text { Plasma } \\
\text { Concentration }\end{array}$ & $\begin{array}{c}\text { Standard } \\
\text { Error } \\
\text { Plasma } \\
\text { Concentration }\end{array}$ & p-value & $\begin{array}{c}\text { Predicted } \\
\text { QTc } \\
\text { at Average } \\
\begin{array}{c}\mathbf{C}_{\max } \\
\mathbf{1 7 4 6 . 8} \mathbf{n g} / \mathrm{L}\end{array}\end{array}$ & $\begin{array}{c}\text { One-sided } \\
\text { Upper 95\% } \\
\text { Confidence } \\
\text { Bound of } \\
\text { Predicted QTc }\end{array}$ & $\begin{array}{c}\text { Overall } \\
\text { Model } \\
\text { Fit }\end{array}$ \\
\hline QTcl & 0.0004 & 0.0003 & 0.2056 & 4.2393 & 5.0716 & $<.0001$
\end{tabular}

Figure 1 (See legend on next page.) 
(See figure on previous page.)

Figure 1 Placebo- and baseline-corrected change in QTcl. (a) Placebo- and baseline-corrected change in QTcl for each time point in each treatment group. (b) Pharmacokinetic/pharmacodynamics relationship: placebo- and baseline-corrected change in QTcl versus netupitant plasma concentrations and (c) versus palonosetron plasma concentrations.

study investigating the cardiovascular safety of $200 \mathrm{mg}$ fosaprepitant reported no clinically relevant effect on QTc interval at any time after infusion (including aprepitant $\mathrm{t}_{\mathrm{max}}$ ) (Marbury et al. 2009; Emend (aprepitant) Prescribing Information 2006). The cardiovascular safety of another $\mathrm{NK}_{1}$ RA whose development was recently interrupted, casopitant, was evaluated and similarly showed no evidence of QTc prolongation after a 3-day oral regimen (Johnson et al. 2010).

Although 5- $\mathrm{HT}_{3}$ RAs such as dolasetron, ondansetron, and granisetron are perceived as safe by the medical community, cardiovascular issues have been reported. Ondansetron $4 \mathrm{mg}$ has been associated with a statistically significant increased prolongation of QTc at various time points following administration in healthy subjects or surgical patients without additional risk factors for QTc prolongation (Charbit et al. 2005, 2008; Benedict et al. 1996; Zofran (ondansetron hydrochloride) Prescribing Information 2011). Although an adequate QT assessment was not conducted, QT prolongation has been associated with the use of granisetron, as shown in a study by Alidoosti et al. reporting prolongation of PR and QTc, and a decrease in HR in cancer patients (Alidoosti et al. 2009; Kytril (granisetron hydrochloride) Prescribing Information 2011). Dolasetron treatment resulted in doserelated increases in HR, PR intervals, and QRS intervals and a statistically significant increase in QTc interval (Benedict et al. 1996). Based on clinical evidence, dolasetron and the highest dose of ondansetron $(32 \mathrm{mg}$ ) are no longer indicated for CINV prevention due to cardiovascular safety concerns. Contrary to these findings, recent studies, including a formal ICH E14 thorough QT trial, have reported that palonosetron does not prolong the QT interval and does not cause any significant acute change in repolarisation (QTc, corrected QT dispersion [QTcd]) or transmural dispersion indices (TpTe, TpTed, and TpTe/QT) (Dogan et al. 2012; Gonullu et al. 2012; Morganroth et al. 2007). The thorough QT/QTc (ICH E14) study in healthy subjects also demonstrated that palonosetron has no effect on the QT interval (QT/QTc) over the 0.25- to 2.25-mg range of exposure (Morganroth et al. 2007; Aloxi (palonosetron hydrochloride) Prescribing

Table 4 Descriptive statistics of PK parameters for netupitant and palonosetron

\begin{tabular}{|c|c|c|c|}
\hline Netupitant & $\mathrm{AUC}_{0-\mathrm{t}}(\mathrm{h} * \mu \mathrm{g} / \mathrm{L}) \mathrm{Geo}$. Mean (Geo. SD) & $C_{\max }(\mu \mathrm{g} / \mathrm{L})$ Geo. Mean (Geo. SD) & $t_{\max }(h)$ Geo. Mean (Geo. SD) \\
\hline \multicolumn{4}{|l|}{$\mathrm{NEPA}_{200 / 0.5}$} \\
\hline Parent & $4079(1.712)$ & $218.7(1.833)$ & $5.218(1.589)$ \\
\hline M1 & $832.5(1.719)$ & $23.55(1.594)$ & $14.54(1.668)$ \\
\hline M2 & $827.3(1.722)$ & $96.94(1.842)$ & $3.580(1.342)$ \\
\hline M3 & $1348(1.642)$ & $46.73(1.559)$ & $10.70(1.490)$ \\
\hline \multicolumn{4}{|l|}{$\mathrm{NEPA}_{600 / 1.5}$} \\
\hline Parent & $12213(1.925)$ & $647.7(2.205)$ & $6.104(1.474)$ \\
\hline M1 & $2007(1.766)$ & $53.71(1.763)$ & $17.82(1.948)$ \\
\hline M2 & $2155(1.908)$ & $227.8(2.024)$ & $4.131(1.208)$ \\
\hline M3 & $2981(1.707)$ & $101.5(1.822)$ & $11.51(1.555)$ \\
\hline Palonosetron & $\mathrm{AUC}_{0-\mathrm{t}}(\mathrm{h} * \mathrm{ng} / \mathrm{L}) \mathrm{Geo}$. Mean (Geo. SD) & $\mathrm{C}_{\max }(\mathrm{ng} / \mathrm{L})$ Geo. Mean (Geo. SD) & $t_{\max }(h)$ Geo. Mean (Geo. SD) \\
\hline \multicolumn{4}{|l|}{$\overline{N E P A_{200 / 0.5}}$} \\
\hline Parent & $22641(1.241)$ & $821.6(1.277)$ & $5.464(1.437)$ \\
\hline M4 & $541.7(2.916)$ & $72.72(1.379)$ & $3.675(1.764)$ \\
\hline M9 & $416.2(2.158)$ & $105.0(1.383)$ & $1.746(1.348)$ \\
\hline \multicolumn{4}{|l|}{$\mathrm{NEPA}_{600 / 1.5}$} \\
\hline Parent & 67918 (1.210) & $2588(1.239)$ & $4.229(1.693)$ \\
\hline M4 & $5571(1.348)$ & $231.0(1.330)$ & $3.388(1.734)$ \\
\hline M9 & $3973(1.468)$ & $348.9(1.313)$ & $1.781(1.535)$ \\
\hline
\end{tabular}

$\mathrm{AUC}_{0-\mathrm{t}}$, area under the plasma concentration-time curve data from administration until the last sampling point; $\mathrm{C}_{\text {max }}$ maximum plasma concentration; Geo., geometric; $\mathrm{PK}$, pharmacokinetic; $\mathrm{SD}$, standard deviation; $\mathrm{t}_{\max }$ time to $\mathrm{C}_{\max }$.

NEPA $200 / 0.5: 200 \mathrm{mg}$ netupitant $(50 \mathrm{mg}+150 \mathrm{mg})+0.50 \mathrm{mg}$ palonosetron $(1 \times 0.50 \mathrm{mg})$.

$\mathrm{NEPA}_{600 / 1.5}: 600 \mathrm{mg}$ netupitant $(4 \times 150 \mathrm{mg})+1.50 \mathrm{mg}$ palonosetron $(3 \times 0.50 \mathrm{mg})$. 
Table 5 Possibly or probably drug-related adverse events

\begin{tabular}{|c|c|c|c|c|}
\hline $\begin{array}{l}\text { Adverse event } \\
\text { Number of subjects (\%) }\end{array}$ & $\begin{array}{l}\text { Placebo } \\
(\mathrm{N}=50)\end{array}$ & $\begin{array}{l}\mathrm{NEPA}_{200 / 0.5} \\
(\mathrm{~N}=49)\end{array}$ & $\begin{array}{c}\mathrm{NEPA}_{600 / 1.5} \\
(\mathrm{~N}=49)\end{array}$ & $\begin{array}{l}\text { Moxifloxacin } \\
\qquad(\mathrm{N}=49)\end{array}$ \\
\hline \multicolumn{5}{|l|}{ Cardiac disorders } \\
\hline Palpitations & 0 & 0 & $1(2.0)$ & 0 \\
\hline \multicolumn{5}{|l|}{ Gastrointestinal disorders } \\
\hline Abdominal pain upper & 0 & $2(4.1)$ & 0 & 0 \\
\hline Constipation & 0 & $3(6.1)$ & $2(4.1)$ & 0 \\
\hline Dry mouth & $1(2.0)$ & 0 & 0 & 0 \\
\hline Dyspepsia & $1(2.0)$ & 0 & 0 & 0 \\
\hline Flatulence & $1(2.0)$ & 0 & 0 & 0 \\
\hline Nausea & 0 & 0 & 0 & $1(2.0)$ \\
\hline \multicolumn{5}{|c|}{ General disorders and administration-site conditions } \\
\hline Fatigue & 0 & $1(2.0)$ & 0 & $1(2.0)$ \\
\hline Thirst & 0 & 0 & 0 & $1(2.0)$ \\
\hline \multicolumn{5}{|c|}{ Musculoskeletal and connective tissue disorders } \\
\hline Muscle twitching & $1(2.0)$ & 0 & 0 & 0 \\
\hline Pain in extremity & 0 & 0 & $1(2.0)$ & 0 \\
\hline Sensation of heaviness & $1(2.0)$ & 0 & 0 & 0 \\
\hline \multicolumn{5}{|l|}{ Nervous system disorders } \\
\hline Dizziness & $1(2.0)$ & 0 & $1(2.0)$ & $3(6.1)$ \\
\hline Headache & $5(10.0)$ & $2(4.1)$ & $5(10.2)$ & $2(4.1)$ \\
\hline Somnolence & 0 & 0 & $1(2.0)$ & 0 \\
\hline \multicolumn{5}{|l|}{ Psychiatric disorders } \\
\hline Anxiety & 0 & 0 & $1(2.0)$ & 0 \\
\hline Euphoric mood & 0 & 0 & $1(2.0)$ & 0 \\
\hline Total & $9(18.0)$ & $8(16.3)$ & $10(20.4)$ & $8(16.3)$ \\
\hline
\end{tabular}

NEPA $_{200 / 0.5}: 200 \mathrm{mg}$ netupitant $(50 \mathrm{mg}+150 \mathrm{mg})+0.50 \mathrm{mg}$ palonosetron $(1 \times 0.50 \mathrm{mg})$. NEPA $_{600 / 1.5}: 600 \mathrm{mg}$ netupitant $(4 \times 150 \mathrm{mg})+1.50 \mathrm{mg}$ palonosetron $(3 \times 0.50 \mathrm{mg})$. Percentages are based on $\mathrm{N}$.

Information 2009). Yavas et al. demonstrated no acute effects of palonosetron on heart rate or blood pressure (Yavas et al. 2012).

This thorough ECG trial enrolled 200 healthy subjects to assess the impact of different doses of netupitant + palonosetron on cardiac repolarisation. The supratherapeutic dose of NEPA $\left(\mathrm{NEPA}_{600 / 1.5}\right)$ was used to mimic exposure in healthy subjects that may occur in the target population under the worst circumstances (eg, concomitant liver disease, presence of heart disease, taking more than the prescribed clinical dose, etc.).

The present data demonstrate that different doses of NEPA have no significant effects on QTcl, HR, PR interval duration, QRS interval duration, or cardiac morphology compared with placebo. The validity of this trial was demonstrated by the fact that the moxifloxacin-positive control group showed the expected change in QTc duration to establish assay sensitivity. The placebo group's change from baseline was within $3.0 \mathrm{~ms}$, indicating that spontaneous factors for QTc change are well controlled. A dose-proportional increase in $\mathrm{AUC}_{0-\mathrm{t}}$ and $\mathrm{C}_{\max }$ was observed for both netupitant and palonosetron. Administration of different doses of NEPA was safe and well tolerated in healthy subjects. Most commonly reported TRAEs with NEPA groups were constipation, abdominal pain, and headache. Although TRAEs were slightly more frequent with $\mathrm{NEPA}_{600 / 1.5}$, the dose combination was safe with an acceptable tolerability profile.

This trial was performed in healthy subjects (18-45 years) to eliminate variables that are known to change ECG parameters, such as concomitant drugs and diseases. This study did not assess the cardiac safety of NEPA in cancer patients. However, a phase III study testing NEPA in cancer patients (without any serious cardiovascular disease history or predisposition to cardiac conduction abnormalities) receiving chemotherapy showed that there 
were no cardiac safety concerns for NEPA based on cardiac AEs and ECGs (Hesketh et al. 2014; Aapro et al. 2014; Gralla et al. 2014). Therefore, both in cancer patients and in healthy volunteers NEPA did not show any increased risk in cardiac safety profile.

In conclusion, in this thorough QT trial, different NEPA combinations showed no ECG effects, which should predict a lack of cardiac safety concerns in clinical practice. Treatments were well tolerated.

\section{Abbreviations}

5-HT: 5-hydroxytryptamine; AE: Adverse event; $\mathrm{AUC}_{0-\mathrm{f}}$ : Area under the plasma concentration-time curve from administration until the last sampling point; CINV: Chemotherapy-induced nausea and vomiting; Cls: Confidence intervals; $C_{\max }$ : Maximum plasma concentration; $C_{\max } * \beta$ : Mean maximum effect; HR: Heart rate; LC-MS/MS: Liquid chromatography-tandem mass spectrometry; NEPA: Netupitant and palonosetron; NEPA $200 / 0.5: 200 \mathrm{mg}$ netupitant + $0.5 \mathrm{mg}$ palonosetron; NEPA $600 / 1.5: 600 \mathrm{mg}$ netupitant + $1.5 \mathrm{mg}$ palonosetron; $\mathrm{NK}_{1}$ : Neurokinin 1; PD: Pharmacodynamics; PK: Pharmacokinetic; QTc: Corrected QT interval; QTcB: Frequency correction performed using Bazett formula; QTcd: Corrected QT dispersion; QTcF: Frequency correction performed using Fridericia formula; QTcl: Individually heart rate-corrected QT interval; RA: Receptor antagonist; SE: Standard error; $t_{\text {max: }}$ Maximum plasma concentration; TRAEs: Treatment-related adverse events.

\section{Competing interests}

The authors have full control of all primary data and they agree to allow the journal to review their data if requested. Dr Spinelli and Dr Moresino are employees of Helsinn Healthcare SA, Lugano, Switzerland. Dr Baumann, Dr Timmer, and Dr Schultz were employees of CRS Clinical Research Services Mannheim, the CRO that conducted the study. They received a regular salary by the $C R O$ which, in turn, has received a budget for the study conduct. None of the authors have further conflicts of interests related to the study to declare.

\section{Authors' contributions}

TS: conception and design of the study, acquisition of data, analysis and interpretation of data, drafting and revising of the manuscript. CM: conception and design of the study, acquisition of data, analysis and interpretation of data, drafting and revising of the manuscript. SB: conception and design of the study, acquisition of data, analysis and interpretation of data, drafting and revising of the manuscript. WT: conception and design of the study, acquisition of data, analysis and interpretation of data, drafting and revising of the manuscript. AS conception and design of the study, acquisition of data, analysis and interpretation of data, drafting and revising of the manuscript. All authors read and approved the final manuscript.

\section{Acknowledgements}

The authors are indebted to Joel Morganroth, MD, from eResearch Technology, Philadelphia, Pennsylvania, USA, for his contribution to the study design, data analysis, and manuscript preparation. In addition, the authors would like to thank Silvia Olivari Tilola and Silvia Sebastiani from Helsinn Healthcare SA, Lugano, Switzerland, as well as Jennifer Vanden Burgt, pharmaceutical consultant, and Norman Nagle from EISAI, New Jersey, USA, for critically reviewing the manuscript. The trial was sponsored by Helsinn Healthcare SA, Lugano, Switzerland. Editorial and medical writing assistance was provided by Margot Eggermont, PhD, and Sandra Mendes, PhD, CMPP, both from TRM Oncology, The Hague, The Netherlands, and funded by Helsinn Healthcare SA, Lugano, Switzerland.

\section{Author details}

'Helsinn Healthcare SA, Via Pian Scairolo 9, 6912 Lugano/Pazzallo, Switzerland. ${ }^{2} \mathrm{CRS}$ Clinical Research Services Mannheim GmbH, Grenadierstrasse 1, 68167 Mannheim, Germany.

Received: 10 April 2014 Accepted: 17 July 2014

Published: 29 July 2014

\section{References}

Aapro MS, Macciocchi A, Gridelli C (2005) Palonosetron improves prevention of chemotherapy-induced nausea and vomiting in elderly patients. I Support Oncol 3(5):369-374

Aapro MS, Grunberg SM, Manikhas GM, Olivares G, Suarez T, Tjulandin SA, Bertoli LF, Yunus F, Morrica B, Lordick F, Macciocchi A (2006) A phase III, double-blind, randomized trial of palonosetron compared with ondansetron in preventing chemotherapy-induced nausea and vomiting following highly emetogenic chemotherapy. Ann Oncol 17(9):1441-1449

Aapro M, Molassiotis A, Dicato M, Peláez I, Rodríguez-Lescure Á, Pastorelli D, Ma L, Burke T, Gu A, Gascon P, Roila F, PEER investigators (2012) The effect of guideline-consistent antiemetic therapy on chemotherapy-induced nausea and vomiting (CINV): the Pan European Emesis Registry (PEER). Ann Oncol 23(8):1986-1992

Aapro M, Rugo H, Rossi G, Rizzi G, Borroni ME, Bondarenko I, Sarosiek T, Oprean C, Cardona-Huerta S, Lorusso V, Karthaus M, Schwartzberg L, Grunberg S (2014) A randomized phase III study evaluating the efficacy and safety of NEPA, a fixed-dose combination of netupitant and palonosetron, for prevention of chemotherapy-induced nausea and vomiting following moderately emetogenic chemotherapy. Ann Oncol 25(7):1328-1333

Alidoosti A, Taslimi F, Ameri A, Sheibani KM, Miri R, Yavari P (2009) Electrocardiographic changes after granisetron administration for chemotherapy induced nausea and vomiting. Acta Medica Iranica 47(4):289-292

Aloxi (palonosetron HCl). Prescribing Information (2009). Helsinn Healthcare SA, Lugano, Switzerland, Available online http://www.aloxi.com/docs/pdf/PI.pdf. Accessed 8 July 2014

Bagnes C, Panchuk PN, Recondo G (2010) Antineoplastic chemotherapy induced QTC prolongation. Curr Drug Saf 5(1):93-96

Basch E, Prestrud AA, Hesketh PJ, Kris MG, Feyer PC, Somerfield MR, Chesney M, Clark-Snow RA, Flaherty AM, Freundlich B, Morrow G, Rao KV, Schwartz RN, Lyman GH, American Society of Clinical Oncology (2011) Antiemetics: American Society of Clinical Oncology clinical practice guideline update. J Clin Oncol 29(31):4189-4198

Benedict CR, Arbogast R, Martin L, Patton L, Morrill B, Hahne W (1996) Single-blind study of the effects of intravenous dolasetron mesylate versus ondansetron on electrocardiographic parameters in normal volunteers. J Cardiovasc Pharmacol 28(1):53-59

Bloechl-Daum B, Deuson RR, Mavros P, Hansen M, Herrstedt J (2006) Delayed nausea and vomiting continue to reduce patients' quality of life after highly and moderately emetogenic chemotherapy despite antiemetic treatment. J Clin Oncol 24(27):4472-4478

Charbit B, Albaladejo P, Funck-Brentano C, Legrand M, Samain E, Marty J (2005) Prolongation of QTc interval after postoperative nausea and vomiting treatment by droperidol or ondansetron. Anesthesiology 102(6):1094-1100

Charbit B, Alvarez JC, Dasque E, Abe E, Démolis JL, Funck-Brentano C (2008) Droperidol and ondansetron-induced QT interval prolongation: a clinical drug interaction study. Anesthesiology 109(2):206-212

Cohen L, de Moor CA, Eisenberg P, Ming EE, Hu H (2007) Chemotherapy-induced nausea and vomiting: incidence and impact on patient quality of life at community oncology settings. Support Care Cancer 15(5):497-503

Dogan U, Yavas G, Tekinalp M, Yavas C, Ata OY, Ozdemir K (2012) Evaluation of the acute effect of palonosetron on transmural dispersion of myocardial repolarization. Eur Rev Med Pharmacol Sci 16(4):462-468

Eisenberg P, Figueroa-Vadillo J, Zamora R, Charu V, Hajdenberg J, Cartmell A, Macciocchi A, Grunberg S, 99-04 Palonosetron Study Group (2003) Improved prevention of moderately emetogenic chemotherapy-induced nausea and vomiting with palonosetron, a pharmacologically novel 5-HT3 receptor antagonist: results of a phase III, single-dose trial versus dolasetron. Cancer 98(11):2473-2482

Emend (aprepitant). Prescribing Information (2006). Merck \& Co, Inc, Whitehouse Station, NJ, Available online http://www.merck.com/product/usa/pi_circulars/ e/emend/emend_pi.pdf. Accessed 8 July 2014

Feyer P, Jordan K (2011) Update and new trends in antiemetic therapy: the continuing need for novel therapies. Ann Oncol 22(1):30-38

Gonullu G, Demircan S, Demirag MK, Erdem D, Yucel I (2012) Electrocardiographic findings of palonosetron in cancer patients. Support Care Cancer 20(7):1435-1439, doi: 10.1007/s00520-011-1226-5

Gralla R, Lichinitser M, Van Der Vegt S, Sleeboom H, Mezger J, Peschel C, Tonini G, Labianca R, Macciocchi A, Aapro M (2003) Palonosetron improves prevention of chemotherapy-induced nausea and vomiting following 
moderately emetogenic chemotherapy: results of a double-blind randomized phase III trial comparing single doses of palonosetron with ondansetron. Ann Oncol 14(10):1570-1577

Gralla RJ, Roila F, Tonato M, Herrstedt J (2013) MASCC/ESMO antiemetic guideline., Available online. http://www.mascc.org/antiemetic-guidelines. Accessed 8 July 2014

Gralla RJ, Bosnjak SM, Hontsa A, Balser C, Rizzi G, Rossi G, Borroni ME, Jordan K (2014) A phase III study evaluating the safety and efficacy of NEPA, a fixed-dose combination of netupitant and palonosetron, for prevention of chemotherapy-induced nausea and vomiting over repeated cycles of chemotherapy. Ann Oncol 25(7):1333-1339

Haab F, Braticevici B, Krivoborodov G, Palmas M, Zufferli Russo M, Pietra C (2014) Efficacy and safety of repeated dosing of netupitant, a neurokinin-1 receptor antagonist, in treating overactive bladder. Neurourol Urodyn 33(3):335-340

Hedhli N, Russell KS (2011) Cardiotoxicity of molecularly targeted agents. Curr Cardiol Rev 7(4):221-233

Hesketh PJ, Van Belle S, Aapro M, Tattersall FD, Naylor RJ, Hargreaves R, Carides $A D$, Evans JK, Horgan KJ (2003) Differential involvement of neurotransmitters through the time course of cisplatin-induced emesis as revealed by therapy with specific receptor antagonists. Eur J Cancer 39(8):1074-1080

Hesketh PJ, Rossi G, Rizzi G, Palmas M, Alyasova A, Bondarenko I, Lisyanskaya A, Gralla RJ (2014) Efficacy and safety of NEPA, an oral combination of netupitant and palonosetron, for prevention of chemotherapy-induced nausea and vomiting following highly emetogenic chemotherapy: a randomized dose-ranging pivotal study. Ann Oncol 25(7):1340-1346

Johnson BM, Adams LM, Zhang K, Gainer SD, Kirby LC, Blum RA, Apseloff G, Morrison RA, Schutz RA, Lebowitz PF (2010) Ketoconazole and rifampin significantly affect the pharmacokinetics, but not the safety or QTc interval, of casopitant, a neurokinin-1 receptor antagonist. J Clin Pharmacol 50(8):951-959

Kytril (granisetron hydrochloride). Prescribing Information (2011). Genentech USA, Inc, South San Francisco, CA, Available online http://www.gene.com/ download/pdf/kytril_injection_prescribing.pdf. Accessed 8 July 2014

Marbury TC, Jin B, Panebianco D, Murphy MG, Sun H, Evans JK, Han TH, Constanzer ML, Dru J, Shadle CR (2009) Lack of effect of aprepitant or its prodrug fosaprepitant on QTc intervals in healthy subjects. Anesth Analg 109 (2):418-425

Morganroth J, Parisi S, Spinelli T, Moresino C, Thorn M, Cullen MT (2007) High-dose palonosetron does not alter ECG parameters including QTC interval in healthy subjects: results of a dose-response, double-blind, randomized, parallel E14 study of palonosetron vs moxifloxacin or placebo. 14th European Conference of Clinical Oncology (ECCO); 23-27 September; Barcelona, Spain

National Comprehensive Cancer Network (2013) NCCN clinical practice guidelines in oncology (NCCN guidelines) antiemesis version 1.2013. Available online. http://www.nccn.org/professionals/physician_gls/pdf/ antiemesis.pdf. Accessed 8 July 2014

Reddy GK, Gralla RJ, Hesketh PJ (2006) Novel neurokinin-1 antagonists as antiemetics for the treatment of chemotherapy-induced emesis. Support Cancer Ther 3(3):140-142

Roila F, Herrstedt J, Aapro M, Gralla RJ, Einhorn LH, Ballatori E, Bria E, Clark-Snow RA, Espersen BT, Feyer P, Grunberg SM, Hesketh PJ, Jordan K, Kris MG, Maranzano E, Molassiotis A, Morrow G, Olver I, Rapoport BL, Rittenberg C, Saito M, Tonato M, Warr D, ESMO/MASCC Guidelines Working Group (2010) Guideline update for MASCC and ESMO in the prevention of chemotherapyand radiotherapy-induced nausea and vomiting: results of the Perugia consensus conference. Ann Oncol 21(Suppl 5):v232-v243

Rojas C, Slusher BS (2012) Pharmacological mechanisms of 5- $\mathrm{HT}_{3}$ and tachykinin $\mathrm{NK}_{1}$ receptor antagonism to prevent chemotherapy-induced nausea and vomiting. Eur J Pharmacol 684(1-3):1-7

Roscoe JA, Morrow GR, Hickok JT, Mustian KM, Shelke AR (2004) Biobehavioral factors in chemotherapy-induced nausea and vomiting. J Natl Compr Canc Netw 2(5):501-508

Rubenstein EB, Slusher BS, Rojas C, Navari RM (2006) New approaches to chemotherapy-induced nausea and vomiting: from neuropharmacology to clinical investigations. Cancer J 12(5):341-347

Saito M, Aogi K, Sekine I, Yoshizawa H, Yanagita Y, Sakai H, Inoue K, Kitagawa C, Ogura T, Mitsuhashi S (2009) Palonosetron plus dexamethasone versus granisetron plus dexamethasone for prevention of nausea and vomiting during chemotherapy: a double-blind, double-dummy, randomised, comparative phase III trial. Lancet Oncol 10(2):115-124, Erratum in: (2010) Lancet Oncol 11(3):226

Salsman JM, Grunberg SM, Beaumont JL, Rogers M, Paul D, Clayman ML, Cella D (2012) Communicating about chemotherapy-induced nausea and vomiting: a comparison of patient and provider perspectives. J Natl Compr Canc Netw 10(2):149-157

Sorrentino MF, Kim J, Foderaro AE, Truesdell AG (2012) 5-fluorouracil induced cardiotoxicity: review of the literature. Cardiol J 19(5):453-458

Spinelli T, Calcagnile S, Giuliano C, Rossi G, Lanzarotti C, Mair S, Stevens L, Nisbet I (2014) Netupitant PET imaging and ADME studies in humans. J Clin Pharmacol 54(1):97-108

Stathis M, Pietra C, Rojas C, Slusher BS (2012) Inhibition of substance P-mediated responses in NG108-15 cells by netupitant and palonosetron exhibit synergistic effects. Eur J Pharmacol 689(1-3):25-30

US Department of Health and Human Services (2005) Guidance for industry. E14 clinical evaluation of QT/QTc interval prolongation and proarrhythmic potential for non-antiarrhythmic drugs (ICH E14)., Available online. http://www.fda.gov/downloads/Drugs/GuidanceComplianceRegulatory Information/Guidances/ucm073153.pdf. Accessed 8 July 2014

Vo TT, Nelson JJ (2012) Cardiovascular events in cancer patients treated with highly or moderately emetogenic chemotherapy: results from a population-based study. J Cancer Epidemiol 2012:529357

Yavas C, Dogan U, Yavas G, Araz M, Ata OY (2012) Acute effect of palonosetron on electrocardiographic parameters in cancer patients: a prospective study. Support Care Cancer 20(10):2343-2347

Yeh ET, Bickford CL (2009) Cardiovascular complications of cancer therapy: incidence, pathogenesis, diagnosis, and management. J Am Coll Cardiol 53(24):2231-2247

Zofran (ondansetron hydrochloride) Prescribing Information (2011) Research Triangle Park, NC: GlaxoSmithKline., Available online http://us.gsk.com/ products/assets/us_zofran.pdf. Accessed 8 July 2014

\section{doi:10.1186/2193-1801-3-389}

Cite this article as: Spinelli et al:: Effects of combined netupitant and palonosetron (NEPA), a cancer supportive care antiemetic, on the ECG of healthy subjects: an ICH E14 thorough QT trial. SpringerPlus 2014 3:389.

\section{Submit your manuscript to a SpringerOpen ${ }^{\circ}$ journal and benefit from:}

- Convenient online submission

- Rigorous peer review

- Immediate publication on acceptance

- Open access: articles freely available online

- High visibility within the field

- Retaining the copyright to your article

Submit your next manuscript at springeropen.com 